\title{
RETRACTED ARTICLE: Removing Artifacts from Raw Electrocardiogram Signals Using Adaptive Filter in State Space
}

\author{
Amjad Zia Khan ${ }^{1}$ (D) Imran Shafi ${ }^{2}$
}

Received: 27 May 2018 / Revised: 18 May 2019 / Accepted: 21 May 2019 / Published online: 27 May 2019 (c) Springer Science+Business Media, LLC, part of Springer Nature 2020

The authors have retracted this article [1] because Figures 1, 2, 3, 4, 7B, 17 and Tables 1 and 2 were duplicated and additional content was adapted from a previously published article by Razzaq et al [2], without the permission of the authors of [2] . All authors of [1] agree to this retraction.

\section{References}

1. A.Z. Khan, I. Shafi, Circuits Syst. Signal Process. (2019). https://doi.org/10.1007/s00034-019-011493.

2. N. Razzaq et al., IEEE Access (2016). https://doi.org/10.1109/ACCESS.2016.2548362.

Publisher's Note Springer Nature remains neutral with regard to jurisdictional claims in published maps and institutional affiliations.

Electronic supplementary material The online version of this article (https://doi.org/10.1007/s00034019-01149-3) contains supplementary material, which is available to authorized users.

$凶$ Amjad Zia Khan

amxian@gmail.com

Imran Shafi

imranshafi@ceme.nust.edu.pk

1 Department of Electrical Engineering, Abasyn University Islamabad Campus, Peshawar, Pakistan

2 National University of Sciences and Technology (NUST), Islamabad, Pakistan 